\title{
JUVENTUDES, TRABALHO E EDUCAÇÃO: UMA TRÍADE ESTRUTURANTE PARA O FENÔMENO DA JUVENILIZAÇÃO DA EJA NO BRASIL?
}

\section{YOUTH, LABOR AND EDUCATION: A STRUCTURING TRIAD FOR THE EJA (YOUTH AND ADULT EDUCATION) JUVENILIZATION PHENOMENON IN BRAZIL?}

José Humberto da Silva ${ }^{1}$

\section{RESUMO}

Este artigo trata de um estudo sobre a juventude brasileira, sua relação com o trabalhoeducação, bem como sobre o processo de inserção de jovens na Educação de Jovens Adultos e o fenômeno da Juvenilização nessa modalidade de ensino. O caminho metodológico aglutinou método e técnicas de pesquisa numa abordagem que articulou dados quantitativos com fontes teóricas já produzidas. Entre os autores referenciados, destacam-se: Bourdieu (1983), Pais (1990), Alves (2008) Sposito (2002), Silva (2008, 2012), Haddad e Di Pierro (2000), Paiva (1987), Brunel (2004), Rummert (2007), entre outros. Acionou-se ao campo teórico o levantamento e análise na base de dados do Instituto Brasileiro de Geografia e Estatística (IBGE) - Pesquisa Nacional por Amostra de Domicílio (PNAD) - e dados do Instituto Nacional de Estudos e Pesquisas Educacionais Anísio Teixeira (INEP) - Ministério da Educação (MEC). O resultado e a análise, oriundos da triangulação dos dados, estão organizados, além da Introdução e Conclusão, em quatro seções, a saber: "Juventude: um conceito ainda em construção"; "Juventude(s) - tempo destinado para a escolarização?"; "Juventude Brasileira e sua relação com o Trabalho - Educação" e, por fim "Juvenilização da EJA". Em linhas gerais, a pesquisa informa que a relação estabelecida pela juventude brasileira ao longo dos anos com o trabalho e a educação é estruturante para consolidação e permanência do fenômeno da Juvenilização da EJA.

PALAVRAS-CHAVE: Juventude; Jovens; Trabalho-Educação; Juvenilização da EJA.

\section{ABSTRACT}

The present article addresses a study on the Brazilian youth, its relation to labor-education, and analyses the process of youth inclusion in the Youth and Adult Education, as well as the Juvenilization phenomenon that surrounds this teaching method. The methodological path of this article gathered methods and techniques of scientific research in an approach that considered both quantitative data and theoretical sources already produced. Among the authors referenced in this research, Bourdieu (1983), Pais (1990), Alves (2008) Sposito (2002), Silva (2008, 2012), Haddad and Di Pierro (2000), Paiva (1987), Brunel (2004) and Rummert (2007) stand out from other researchers. The survey and analysis of data were

\footnotetext{
1 Professor Titular da Universidade do Estado da Bahia (UNEB) - Departamento de Educação, DEDC/Campus I - Programa de Pós Graduação em Educação de Jovens e Adultos - MPEJA . Doutor em Educação pela Unicamp e Líder do Grupo de Pesquisa Formação, Trabalho e Identidades (FORTIS). Bahia, BA, Brasil. e-mail: zeuneb@hotmail.com; jhsilva@uneb.br
} 
added to the theoretical field, especially the databases from IBGE (Brazilian Institute of Geography and Statistics) - National Survey by Household Sampling (PNAD) - and the National Institute for Educational Studies and Research "Anísio Teixeira" (INEP) - Ministry of Education (MEC). The analysis and result of this research, deriving from data triangulation, are organized - besides the Introduction and a Conclusion - in four sections as follows: "Youth: a concept still under construction"; "Youth - time allocated for schooling?"; "Brazilian youth and its relation to Labor-Education" and, finally, "EJA Juvenilization". In general terms, this article informs that there is a relationship between the Brazilian youth with labor and education, which is structuring to consolidate and perpetuate the EJA Juvenilization phenomenon.

KEYWORDS: Youth; Young people; Labor-Education; EJA Juvenilization.

\section{INTRODUÇÃO}

A Educação de Jovens e Adultos (EJA) é uma das modalidades de ensino da Educação Básica no Brasil. Tradicionalmente, é caracterizada pelo atendimento àqueles que não tiveram a oportunidade de construir trajetórias de escolarização na idade considerada adequada, ou ainda aos que ingressaram na escola, mas não puderam nela permanecer, em virtude de múltiplos fatores nos contextos sociais onde se inscrevem esses sujeitos. A lei de Diretrizes e Bases da Educação Nacional (LDBEN) - Lei no 9394/96 - destaca, no artigo 37, que "A educação de Jovens e Adultos será destinada àqueles que não tiveram acesso ou continuidade de estudos no ensino fundamental e médio na idade própria".

Durante décadas, as salas da EJA no Brasil foram marcadas pela presença, na sua grande maioria, de adultos e idosos - o que, decerto, parece contribuir ainda hoje para associação direta de que essa modalidade de ensino se destina às pessoas na faixa etária mais elevada. Contudo, esse estigma, por mais que persista, precisa ser quebrado, haja vista que os dados de matrículas da EJA, desde meados de 1990, apontam para uma presença significativa e crescente de jovens nessa modalidade de ensino.

Assim, há uma parcela expressiva de jovens que têm acessado a EJA formada não apenas por aqueles que nunca foram à escola - devido a circunstâncias específicas relativas a um dado contexto social -, mas também pelos que frequentaram a escola denominada regular e, por motivos mais diveros, não concluiram suas trajetórias de escolarização na idade/série. Como bem destaca Andrade (2004, p. 50), são jovens que "[...] precisaram abandonar a escola; vivem em periferias, favelas, vilas e bairros pobres, principalmente nas grandes cidades; são majoritariamente negros; circulam no espaço escolar um 'incansável' número de vezes, com entradas, saídas e retornos, após o período estabelecido como o próprio para a vida escolar $[\ldots] " .$. 
A presença expressiva de jovens na EJA vem ganhando destaque nas discussões sobre educação, uma vez que uma parcela significativa juvenil tem construído novas configurações no cotidiano escolar, (re)organizando as relações sociais presentes na modalidade e, principalmente, colocando novos desafios para todos os atores envolvidos.

A partir dos anos 2000, alguns estudos passaram a denominar esse processo como "o fenômeno da juvenilização da EJA", tendo em vista a presença massiva de adolescentes e jovens nas turmas de Educação de Jovens e Adultos, destacadamente nas séries finais do Ensino Fundamental e do Médio. Nessa direção, Brunel (2004) define essa situação como um fenômeno dos anos 1990. Para ela, fatores pedagógicos, políticos, legais e estruturais fazem com que muitos jovens procurem cada vez mais essa modalidade e, a cada ano, mais precocemente.

A juvenilização da EJA, para além de ser um processo relativamente novo, se expressa como um fenômeno complexo - por envolver múltiplos fatores conjunturais e estruturais - e, portanto, precisa ser aprofundada, nos seus múltiplos aspectos, com muito cuidado analítico. Sposito, desde 2002, já indicava que as pesquisas sobre Juventude-Educação, até então, eram inexpressivas, bem como necessitava-se de novas referências teórico-metodológicas e que desdobrassem novos ângulos e questões, ainda não suficientemente exploradas.

Tal empreitada demanda um grande esforço, haja vista que o estudo da própria categoria geradadora do fenômeno - $a(s)$ juventude(s) - torna-se uma complexa tarefa, pelo menos para os estudiosos que a analisam à luz da Sociologia, pois a definição de juventude encerra em si mesma um problema sociológico, na medida em que os critérios que a constituem são múltiplos.

Por ser a juventude uma condição/construção social e, ao mesmo tempo, um tipo de representação, há uma diversidade na própria definição e compreensão da categoria. Portanto, faz-se necessário, antes de tudo indagar: de que Juventude(s) estamos falando? Quem são os jovens brasileiros? Quem é a Juventude que informa esse fenômeno? A Juvenilização da EJA ainda é um fenômeno que persiste?

Para responder às perguntas supracitadas, percorremos um caminho metodológico que aglutinou método e técnicas de pesquisa numa abordagem que articulou dados quantitativos com fontes teóricas já produzidas em outros contextos, fonte essas com outras preocupações e objetivos.

Para tanto, iniciamos o caminho da pesquisa elaborando uma revisão do referencial teórico, considerando os conceitos e as categorias que circunscrevem as questões desta pesquisa. Nesse momento, tornou-se de fundamental importância a recuperação das fontes e produções acadêmicas já existentes que analisam as categorias centrais deste trabalho.

Para efeito deste estudo, a juventude será compreendida, numa perspectiva etária, como um período que se estende até os 29 anos idade. A adoção desse limite 
etário se justifica não só por uma adesão ao marco legal brasileiro², mas, sobretudo, por acreditar que as análises de dados quantitativos coletados (até os 29 anos) podem contribuir para desvelar a real juventude brasileira.

Assim, a investigação do ponto de vista de seus objetivos se caracterizou como analítica-descritiva, haja vista que foram analisadas, de forma descritiva, as características da população juvenil, sua relação com o Trabalho-Educação, bem como o fenômeno da juvenilização da EJA. Sobre as pesquisas descritivas, Gil (2008) destaca que estas têm como objetivo a descrição de características de determinada população ou fenômeno, além do estabelecimento de relações entre variáveis.

$\mathrm{Na}$ discussão sobre as questões pertinentes à juventude, foram utilizadas, como referencial teórico, autores como Bourdieu (1983), Pais (1990), Alves (2008), Sposito (2002), Silva (2012), dentre outros, que articulam o conceito de juventude(s) e culturas juvenis como construções históricas e culturais, possibilitando, ainda, um entendimento sociológico da categoria juventude, favorecendo o entendimento sobre a juvenilização da EJA. Na revisão teórica propriamente dita da Juvenilização da EJA, destacam-se os trabalhos de Haddad e Di Pierro (2000), Paiva (1987), Brunel (2004), Rummert (2007), entre outros, no que se refere à construção histórica e política da educação de jovens e adultos.

Já para coleta quantitativa, foram utilizados os bancos de dados com os levantamentos estatísticos, referentes ao emprego e desemprego juvenil, disponibilizados pelo Instituto Brasileiro de Geografia e Estatística (IBGE) - Pesquisa Nacional por Amostra de Domicílio (PNAD) - e o com os dados de Matrícula na Modalidade de EJA disponibilizados pelo Instituto Nacional de Estudos e Pesquisas Educacionais Anísio Teixeira (INEP), do Ministério da Educação (MEC).

A partir da triangulação desses macrodados com os referenciais teóricos consultados, buscou-se, constantemente, a reflexão sobre as questões problematizadoras, bem como o aprofundamento e a ampliação de outros pontos que somente 0 desenvolvimento da pesquisa permitiu seu desvelamento. A triangulação foi adotada nesta pesquisa por entendermos que o "[...] uso de múltiplos métodos, ou da triangulação, reflete uma tentativa de assegurar uma compreensão em profundidade do fenômeno em questão" (DENZIN \& LINCOLN, 2006, p. 19).

O artigo, resultado desse processo, está estruturado em seis seções, dialogando ora com os dados quantitativos, ora com as fontes teóricas. Por isso, a trajetória da exposição que se segue está organizada em seções distintas, mas

\footnotetext{
${ }^{2}$ Em 2005, passa a ser considerado jovem o cidadão ou cidadã com idade entre 15 e 29 anos, conforme Lei 11.129 de 30/05/2005 e as diretrizes contidas do Plano Nacional da Juventude da Câmara Legislativa Federal e do Conselho Nacional de Juventude (CONSELHO, 2006), sendo com este o recorte etário que vão operar os programas de juventude.
} 
complementares, apresentadas a partir de uma lógica construída que melhor orientou a conformação deste trabalho.

$\mathrm{Na}$ introdução apresentamos a problematização que circunscreve o objeto, as questões centrais de pesquisa e o percurso metodológico, bem com a estrutura do artigo. A segunda seção "Juventude: um conceito ainda em construção" expõe aspectos históricos e conceituais da conformação da Juventude. A seção seguinte, denominada "Juventude(s) - tempo destinado para a escolarização?" apresenta a discussão sobre a juventude moderna como período de moratória social. Depois, na seção, "Juventude Brasileira e sua relação com o Trabalho-Educação", aborda a relação entre trabalho-educação para os jovens, estabelecendo uma demarcação teórica para a juventude trabalhadora brasileira. Já a quinta seção, "A Juvenilização da EJA", analisa a expressiva presença de jovens na EJA, à luz das discussões teóricas e dados quantitativos. Por fim, nas considerações finais recolocam-se as conclusões parciais, retomam-se os resultados da pesquisa, ao mesmo tempo em que informa a complexidade da temática, ressaltando, portanto, a necessidade de novas investigações que possam melhor analisar o objeto em questão.

\section{JUVENTUDE: UM CONCEITO AINDA EM CONSTRUÇÃO}

Desde o final dos anos 1990 e início da década de 2000, verifica-se relevante discussão teórica e analítica acerca da temática juventude e das questões relacionadas aos jovens. Inúmeros são os trabalhos que objetivam definir e categorizar a juventude ${ }^{3}$. No entanto, parece consenso, pelo menos para os estudiosos que a analisam à luz da Sociologia, que esta é uma tarefa complexa, pois a própria definição da categoria juventude encerra em si um problema sociológico, na medida em que os critérios que a constituem são históricos, econômicos e culturais. Por ser a juventude uma condição social e, ao mesmo tempo, um tipo de representação (PERALVA, 1997), há uma diversidade na definição e compreensão dessa categoria. As análises, em sua grande maioria, privilegiam recortes específicos - classe, idade, raça, gênero, geração, entre outros - que diferenciam e singularizam os jovens.

Bourdieu (1983, p. 113), em seu clássico e provocador artigo sobre juventude - "A juventude é apenas uma palavra" - afirma que "divisões entre idades são arbitrárias" (BOURDIEU, 1983, p. 113). Assim, as fronteiras de idades são objetos de disputas sociais para ingresso no mercado de trabalho, na escola, no casamento etc.

O sociólogo português Pais (1990), na tentativa de sistematizar os estudos já realizados no campo da sociologia da juventude, organizou os trabalhos sobre 0 tema em duas grandes correntes de análise: a geracional e a de classe. A primeira tem como ponto de partida a juventude como uma fase da vida, enfatizando a busca

\footnotetext{
${ }^{3}$ Para maior aprofundamento ver: Marília Sposito (2009).
} 
por aspectos característicos mais uniformes e homogêneos que fariam parte de uma cultura juvenil, unitária, específica de uma geração definida em termos etários.

Para a segunda corrente, a juventude é tomada como um conjunto social necessariamente diversificado, perfilando diferentes culturas juvenis, em função das diferentes classes sociais às quais pertencem os jovens. Assim, as culturas juvenis são sempre culturas de classe, uma vez que são compreendidas como produto de relações antagônicas entre classe e/ou de culturas de resistência, enfim, culturas negociadas dentro de um contexto determinado por relações de classe. Mesmo os estilos mais exóticos de comportamento apresentados por jovens, a exemplo de um cabelo punk ou de lábios pintados de roxo, são vistos como forma de resistência às contradições de classe, uma forma de desafiar a ordem estabelecida e a ideologia dominante.

Sposito (1997) destaca que essa polaridade, evidenciada na sistematização elaborada pelo autor português Machado Pais, é estabelecida, a partir dos anos 1960, quando, no interior da Sociologia, se perguntava: a juventude "existe" como um grupo social relativamente homogêneo ou é "apenas" uma palavra?, como afirma Bourdieu (1983). Paralelamente a esse contexto de indagações, aqui no Brasil, uma das pioneiras da sociologia da juventude já demarcava sua compreensão analítica sobre a noção de juventude. Para Foracchi (1965, p. 303), "[...] menos que uma etapa cronológica da vida, menos que uma potencialidade rebelde e inconformada, a juventude sintetiza uma forma possível de pronunciar-se diante do processo histórico e constituí-lo".

Estudiosos mais contemporâneos da temática se esforçam na tentativa de ampliar e pluralizar a Juventude. Assim, para Dayrell (2003), a juventude constitui um momento determinado, mas não se reduz a uma passagem, na verdade, ela assume uma importância em si mesma. Assim, todo o percurso é influenciado pelo meio social concreto no qual se desenvolve e pela qualidade das trocas que ele proporciona (DAYRELL, 2003). Nesse sentido, Carrano (2000) nos convoca a uma compreensão de que é importante analisar a juventude como uma complexidade variável, que se distingue nos diferentes tempos e grupos sociais.

Contudo, um dos grandes perigos que ainda ronda a busca por uma definição de juventude é o fato de que ela não aglutina, necessariamente, grupos homogêneos. Mesmo se forem estabelecidos critérios sócio-históricos, um indivíduo jovem de 17 anos tem características fisiológicas e psicológicas diferentes de um indivíduo jovem de 24 anos. Além disso, a experiência de um jovem morador do sertão nordestino difere essencialmente da experiência de um jovem, da mesma idade, da classe média paulistana. Múltiplos fatores contribuem para uma diferenciação de grupos dentro do grupo maior Juventude, dentre eles religião, classe social, territorialidade, relações de gênero, grupos étnicos, entre outros. 
As desigualdades e heterogeneidades que prevalecem no país são vividas pelos jovens e expressas das mais variadas formas. $O$ acesso aos direitos e aos bens culturais se dá de forma desigual, especialmente quando se considera o que amplia ou restringe as suas possibilidades de acesso à escola e ao trabalho. São diversas juventude(s), imersas em diferentes contextos. As mulheres jovens, os jovens negros de ambos os sexos, assim como os jovens das áreas metropolitanas de baixa renda ou de determinadas zonas rurais são afetados de forma mais severa pela exclusão social, pela falta de oportunidades e pela falta de emprego.

\section{JUVENTUDE(S) - TEMPO DESTINADO PARA A ESCOLARIZAÇÃO?}

Embora sejam diversas e controversas as definições e as perspectivas de análise sobre a temática, parece-nos que há o consenso de que a juventude é um produto histórico da modernidade. De uma modernidade que trouxe consigo a escola para as massas, a demarcação de um tempo específico para aprender, instituiu a crescente intervenção do Estado-Nação na regulação da sociedade, construiu a juventude como uma categoria social e, especialmente, provocou profundas mudanças sociais, muitas delas fizeram nascer um conjunto de problemas que, associados a uma população jovem, contribuíram para que esta se tornasse objeto de consciência social.

Foi essa mesma modernidade que, segundo Silva (2012), solidificou uma concepção de juventude associada ao período de preparação para a vida adulta, principalmente demarcada pelo período de transição da inatividade para o ingresso no sistema produtivo capitalista. Sendo assim, a juventude vem a ser compreendida como uma mera passagem para a maturidade, vivida em uma espécie de "etapa moratória social", cuja tarefa é a preparação para a vida adulta, ou seja, um crédito de tempo concedido a esse segmento para a aquisição de estruturas necessárias à vida adulta ${ }^{4}$.

$\mathrm{Na}$ perspectiva analítica dos estudiosos sobre o assunto, os jovens eram socializados em meio a outras gerações, sendo educados para a vida em contato direto com o adulto. Essa imersão com outros grupos etários não formava a juventude como uma categoria sociologicamente diferenciada. Posteriormente, no entanto, os jovens passaram a ser afastados da vida social, separados em escolas com o objetivo de aprender as normas da vida em sociedade. A partir de então, começam a se estruturar como uma categoria social específica ${ }^{5}$.

\footnotetext{
${ }^{4}$ A compreensão da juventude como "moratória social" associa-se às transformações ocorridas desde o início do século XX, no modelo de socialização dominante na Europa ocidental, especialmente entre as famílias burguesas; modelo cunhado por Erik Erikson e, décadas depois, atualizado pelos sociólogos argentinos Mario Margulis e Marcelo Urresti, como destacou Alves (2008).

${ }^{5}$ Para um aprofundamento sobre o assunto ver Gottlie \& Reeves (1968).
} 
Mantidos fora do sistema produtivo, os jovens passam a viver uma moratória, ou seja, ficam suspensos da vida social, ou, ao menos, do processo produtivo. Para Galland (1996, p. 74) - um dos principais representantes da sociologia francesa sobre juventude -, nesse período de "suspensão", o jovem construiria, assim, "progressivamente, sua identidade social e profissional".

Entretanto, é importante destacar que essa compreensão de juventude, como um tempo de espera e de preparação para uma vida a "vir a ser", não é, nem nunca foi, um privilégio de todos. Mesmo considerando que a juventude já existia no léxico europeu, como afirmou Pais (1993), antes da modernidade, é também possível afirmar que, durante séculos, essa fase da vida foi um privilégio de grupos sociais específicos. Para a socióloga portuguesa Natália Alves (2008, p. 18):

[...] primeiro a aristocracia, depois a burguesia - e que só com a modernidade se verifica a generalização desta fase da vida, dando origem ao que tem vindo a ser designado por juventude moderna. É precisamente, 0 atributo moderno utilizado para qualificar a juventude que permite estabelecer as pontes entre duas posições, que só aparentemente se opõem, distinguindo entre uma experiência juvenil socialmente circunscrita e uma experiência juvenil massificada, característica das sociedades modernas.

Ainda segundo a autora, apesar de ser socialmente minoritária, a juventude aristocrática é a primeira a adquirir visibilidade social, com a publicação de obras consagradas para a sua educação ${ }^{6}$, nos finais do século XVII e início do XVIII. Essas publicações contribuíram não só para a construção dessa nova categoria social, mas também para definir o espaço social onde esse processo irá majoritariamente ocorrer: a educação.

No entanto, ao mesmo tempo que algumas obras retratam a juventude como um grupo social impulsionador de mudanças, outras colocam a tônica nos problemas que Ihe estão associados. Dessa forma, a visibilidade social que a juventude vai, progressivamente, adquirindo perpassa pelo confronto entre estas duas perspectivas de análise.

Circunscritos primeiramente à aristocracia, os problemas ligados à juventude passam a ser associados à nova classe social em consolidação: a burguesia. Os jovens burgueses são os primeiros a usufruir da escola de massas, a investir no prolongamento das trajetórias escolares e a contribuir para que a juventude passe a ser associada a um período de preparação para a vida adulta.

\footnotetext{
${ }^{6}$ Esta visibilidade social será um elemento essencial na construção da Juventude Moderna.
} 
Assim, se por um lado a modernidade trouxe para alguns o tempo e o lugar para aprender, por outro acarretou, para uma grande maioria de jovens, problemas construídos no interior de uma sociedade capitalista, como pobreza, exploração econômica, delinquência e marginalidade. Porém, a natureza desses mesmos problemas e a ameaça que eles constituem para ordem social estabelecida e o tipo de jovens sobre os quais eles incidem - o jovem pobre - permitem afirmar que a constituição social da juventude moderna comporta, em si, uma "marca de classe".

Portanto, se é verdade que, ao longo do século $X X$, esses problemas foram se reconfigurando, dando lugar a novos fenômenos sociais, é igualmente verdade que, no início do século XXI, não desapareceram nem os problemas nem o grupo social mais atingido: a juventude. Os problemas foram se metamorfoseando e, junto com eles, a pobreza e a falta de alternativas - sobretudo ligadas à falta do emprego transformaram muitos jovens em vítimas e agentes de violência.

Face ao exposto, é pertinente indagar: será que a compreensão da juventude "como uma mera etapa de transição para a vida adulta" se aplica à grande maioria dos jovens brasileiros que, desde cedo, são obrigados a trabalhar, a conciliar horas de estudos com horas de trabalho (ou à procura dele) e a lidar com as crises e instabilidades do emprego?

\section{JuVENTUde BRASileira e SUA RELAÇÃo COM O TRABALHO-EduCAÇÃo}

Ao observar na Tabela 1 os dados referentes aos anos de 1992, 2001 e 2009, extraídos da $\mathrm{PNAD}^{7}$, pode-se perceber que muitos jovens brasileiros, na faixa etária de 15 a 29 anos, trabalham ou procuram emprego, constituindo um universo populacional (o qual já havíamos denominado, em 2012, de "Juventude Trabalhadora Brasileira)" ${ }^{\prime 8}$. Esses jovens são aqui apresentados em três grupos etários, não somente para organizar e condensar os microdados da análise, mas, sobretudo, porque mantêm características que os diferem e singularizam: jovem adolescente (15-19 anos), jovem (20-24 anos) e jovem adulto (25-29 anos). São aproximadamente 34 milhões de pessoas, segundo a PNAD (2009), que contribuíam efetivamente para geração de riqueza, na condição de empregado ou não, perfazendo nada menos que $70 \%$ da população jovem (ver área sombreada da Tabela 1).

Entretanto, ao observar esta mesma tabela, percebe-se, nos últimos dez anos, uma redução paulatina de jovens entre 15-19 anos que trabalham ou procuram emprego - de 49, 7\% em 2001 para 47,4\% em 2009 -, diminuição ocasionada principalmente pelas políticas sociais de acesso à escola pública. Mesmo assim, foi

\footnotetext{
${ }^{7}$ O objetivo foi fazer um recorte temporal maior de análise. Os dados dos anos de 2018 não entraram para análise porque ainda não tinham sido disponibilizados no período de coleta.

${ }^{8}$ Para um maior aprofundamento, consultar Silva (2012)
} 
muito expressiva a quantidade de jovens adolescentes (15-19 anos) que estavam trabalhando ou procurando emprego - 59,7\% em 1992 (PNAD), ou seja, 12,3\% a mais que no ano de 2009. Faz-se necessário destacar que a década de 1990 foi um período de recessão econômica ${ }^{9}$ e desemprego, por isso, uma parte significativa da população brasileira, principalmente os jovens, buscou no emprego as possibilidades básicas de sobrevivência.

Para os jovens (20-24 anos) e jovens adultos (25-29 anos) houve, no período em análise, um aumento daqueles que estavam trabalhando ou procurando emprego. Ressaltamos que não se pode medir o desemprego dentro do agrupamento de jovens entre 15-19 anos, pois, em tese, eles estariam frequentando a escola, já os jovens entre 20-29 anos são representativos para evidenciar o fenômeno do desemprego juvenil. Percebemos que o desemprego não diminuiu significativamente no período de análise entre os jovens de (20-24 anos), pois era de $11,4 \%$, em 2001 , e foi para $11,6 \%$ no ano de 2009. Já para os jovens adultos (2529 anos), de $8,1 \%$, em 2001, cresceu para $8,4 \%$.

Tabela 1 - Distribuição da população jovem, segundo a situação de trabalho e estudo e faixa etária. Brasil ${ }^{1}$, $1992-2009$ (em \%)

\begin{tabular}{|c|c|c|c|c|}
\hline \multirow[b]{2}{*}{ Situação } & \multicolumn{4}{|c|}{ Faixa etária (em anos) } \\
\hline & $15-19$ & $20-24$ & $\begin{array}{l}25- \\
29\end{array}$ & $15-29$ \\
\hline \multicolumn{5}{|l|}{1992} \\
\hline Trabalha e não estuda & 32,0 & 57,6 & 68,2 & 51,4 \\
\hline Trabalha e estuda & 19,7 & 10,1 & 4,2 & 11,9 \\
\hline Desempregado e estuda & 4,3 & 1,7 & 0,4 & 2,3 \\
\hline Desempregado e não estuda & 3,7 & 6,2 & 4,8 & 4,9 \\
\hline Apenas estuda & 26,7 & 5,1 & 1,1 & 11,9 \\
\hline $\begin{array}{l}\text { Não trabalha, não procura } \\
\text { trabalho e não estuda }\end{array}$ & 13,5 & 19,3 & 21,2 & 17,7 \\
\hline Total & 100,0 & 100,0 & 100,0 & 100,0 \\
\hline \multicolumn{5}{|l|}{2001} \\
\hline Trabalha e não estuda & 16,6 & 49,0 & 63,1 & 41,0 \\
\hline Trabalha e estuda & 22,3 & 14,8 & 8,6 & 15,8 \\
\hline Desempregado e estuda & 6,9 & 3,3 & 1,2 & 4,0 \\
\hline Desempregado e não estuda & 3,9 & 8,1 & 6,9 & 6,2 \\
\hline Apenas estuda & 39,7 & 8,1 & 2,5 & 18,3 \\
\hline $\begin{array}{l}\text { Não trabalha, não procura } \\
\text { trabalho e não estuda }\end{array}$ & 10,5 & 16,8 & 17,7 & 14,7 \\
\hline Total & 100,0 & 100,0 & 100,0 & 100,0 \\
\hline \multicolumn{5}{|l|}{2009} \\
\hline Trabalha e não estuda & 16,1 & 52,7 & 66,3 & 44,8 \\
\hline Trabalha e estuda & 20,3 & 14,3 & 9,0 & 14,5 \\
\hline Desempregado e estuda & 6,7 & 2,8 & 1,1 & 3,6 \\
\hline
\end{tabular}

\footnotetext{
${ }^{9}$ Na seção seguinte, este período será abordado com mais profundidade.
} 
DOI: $10.12957 /$ e-mosaicos.2019.46588

\begin{tabular}{lllll} 
Desempregado e não estuda & 4,3 & 8,8 & 7,3 & $\mathbf{6 , 8}$ \\
Apenas estuda & 43,1 & 7,2 & 2,1 & $\mathbf{1 7 , 7}$ \\
Não trabalha, não procura & 9,6 & 14,2 & 14,2 & $\mathbf{1 2 , 6}$ \\
trabalho e não estuda & 100,0 & 100,0 & 100,0 & $\mathbf{1 0 0 , 0}$ \\
\hline Total & & & &
\end{tabular}

(1) Exclusive áreas rurais da região Norte.

Fonte: IBGE - PNAD. Elaboração própria.

Os dados apresentados na Tabela 1 revelam que o conceito de juventude como um momento de espera e preparação para a vida adulta - ancorados na noção de moratória social -, caso ainda seja aplicável aqui no Brasil, restringe-se a uma parcela da população jovem brasileira que possui o privilégio de ter seus estudos custeados por seus pais e/ou parentes. Em resumo, vê-se que esse privilégio atinge $17,7 \%$ dos jovens de idade entre 15-29 anos. Esse percentual se torna ainda menor na medida em que a faixa etária vai aumentando: $7,2 \%$, no caso de jovens de 20 a 24 anos, e $2,1 \%$ entre os jovens adultos de 25 a 29 anos.

Tabela 2 - Distribuição da população jovem, segundo a situação de trabalho e estudo e faixa etária. Brasil ${ }^{1}$, 1992-2009 (em \%)

\begin{tabular}{|c|c|c|c|c|c|c|c|c|}
\hline \multirow{2}{*}{ Situação } & \multicolumn{4}{|c|}{ Masculino } & \multicolumn{4}{|c|}{ Feminino } \\
\hline & $15-19$ & 20-24 & 25-29 & 15-29 & $15-19$ & 20-24 & 25-29 & 15-29 \\
\hline \multicolumn{9}{|l|}{1992} \\
\hline Trabalha e não estuda & 41,7 & 73,3 & 86,5 & 65,4 & 22,3 & 42,1 & 51,3 & 37,7 \\
\hline Trabalha e estuda & 23,2 & 10,3 & 4,3 & 13,3 & 16,2 & 10,0 & 4,2 & 10,5 \\
\hline Desempregado e estuda & 4,4 & 1,7 & 0,3 & 2,3 & 4,3 & 1,7 & 0,5 & 2,3 \\
\hline Desempregado e não estuda & 3,8 & 6,3 & 4,6 & 4,9 & 3,7 & 6,1 & 4,9 & 4,9 \\
\hline \multirow{3}{*}{$\begin{array}{l}\text { Apenas estuda } \\
\text { Não trabalha, não procura trabalho } \\
\text { e não estuda } \\
\text { Total }\end{array}$} & 20,4 & 3,4 & 0,5 & 8,9 & 33,0 & 6,7 & 1,7 & 14,7 \\
\hline & 6,4 & 5,0 & 3,7 & 5,2 & 20,5 & 33,4 & 37,4 & 29,9 \\
\hline & 100,0 & 100,0 & 100,0 & 100,0 & 100,0 & 100,0 & 100,0 & 100,0 \\
\hline \multicolumn{9}{|l|}{2001} \\
\hline Trabalha e não estuda & 21,0 & 61,2 & 78,3 & 50,9 & 12,2 & 37,3 & 48,8 & 31,5 \\
\hline Trabalha e estuda & 27,5 & 16,1 & 9,0 & 18,4 & 17,1 & 13,5 & 8,2 & 13,3 \\
\hline Desempregado e estuda & 7,1 & 3,4 & 1,1 & 4,1 & 6,7 & 3,2 & 1,4 & 4,0 \\
\hline Desempregado e não estuda & 3,7 & 7,1 & 5,8 & 5,4 & 4,1 & 8,9 & 7,9 & 6,9 \\
\hline \multirow{3}{*}{$\begin{array}{l}\text { Apenas estuda } \\
\text { Não trabalha, não procura trabalho } \\
\text { e não estuda } \\
\text { Total }\end{array}$} & 35,2 & 6,1 & 1,1 & 15,7 & 44,3 & 10,0 & 3,9 & 20,7 \\
\hline & 5,5 & 6,1 & 4,7 & 5,5 & 15,5 & 27,0 & 29,9 & 23,7 \\
\hline & 100,0 & 100,0 & 100,0 & 100,0 & 100,0 & 100,0 & 100,0 & 100,0 \\
\hline \multicolumn{9}{|l|}{2009} \\
\hline Trabalha e não estuda & 20,7 & 63,9 & 78,2 & 53,7 & 11,5 & 41,5 & 55,0 & 36,0 \\
\hline Trabalha e estuda & 24,0 & 14,5 & 9,2 & 16,1 & 16,4 & 14,0 & 8,8 & 13,1 \\
\hline Desempregado e estuda & 6,3 & 2,4 & 0,8 & 3,2 & 7,1 & 3,3 & 1,4 & 3,9 \\
\hline
\end{tabular}


DOI: $10.12957 / \mathrm{e}-\mathrm{mosaicos} .2019 .46588$

$\begin{array}{lllllllll}\text { Desempregado e não estuda } & 4,1 & 7,2 & 5,9 & \mathbf{5 , 7} & 4,5 & 10,4 & 8,7 & \mathbf{7 , 8} \\ \text { Apenas estuda } & 38,5 & 5,4 & 1,2 & \mathbf{1 5 , 4} & 47,7 & 9,0 & 2,9 & \mathbf{1 9 , 9} \\ \text { Não Trabalha, não procura } & 6,5 & 6,6 & 4,8 & \mathbf{6 , 0} & 12,8 & 21,9 & 23,2 & \mathbf{1 9 , 3} \\ \text { trabalho e não estuda } & 100,0 & 100,0 & 100,0 & \mathbf{1 0 0 , 0} & 100,0 & 100,0 & 100,0 & \mathbf{1 0 0 , 0} \\ \text { Total } & & & & & & \end{array}$

Fonte: IBGE - PNAD. Elaboração própria.

(1) Exclusive áreas rurais da região Norte.

Fonte: IBGE - PNAD. Elaboração própria.

Observando os dados da Tabela 2, no que se refere à distribuição da população jovem segundo a situação de trabalho, estudo e sexo, percebem-se algumas singularidades. Primeiramente, a situação das jovens é bastante desfavorável em comparação ao segmento masculino. O desemprego é maior entre as mulheres jovens do que entre os homens, isso em todos os agrupamentos etários: jovens adolescentes (15-19 anos), jovens (20-25 anos) e jovens adultas (2529 anos). De fato, houve um crescimento significativo de mulheres desempregadas nas últimas décadas: de $7,1 \%$ do total de mulheres desempregadas em 1992 para $11 \%$ em 2009.

As mulheres jovens não apenas têm contribuído para um maior peso entre os desempregados, como também vivem um crescente distanciamento das possibilidades de inserção ocupacional, quando comparadas aos jovens do sexo masculino. Por outro lado, a elevada participação das mulheres no contingente dos desempregados jovens mostra que uma parcela importante desse grupo populacional sai de uma condição de inatividade para desempregado, configurando o que se convencionou denominar como "a feminização do desemprego juvenil"10.

Porém, embora os índices de participação na força de trabalho venham aumentando nas últimas décadas, no grupo dos inativos ${ }^{11}$, as mulheres jovens também são maioria em todos os agrupamentos juvenis. É importante evidenciar que muitas mulheres aqui "classificadas" como inativas acumulam a frequência à escola com atividades que Ihes são atribuídas desde criança, a exemplo do trabalho doméstico. Sendo assim, não é legítimo afirmar que uma parte significativa da população juvenil do sexo feminino viva a juventude como uma mera etapa de transição para a vida adulta.

No tocante ao recorte "cor" (Tabela 3), verifica-se que a juventude trabalhadora se encontra de forma bastante desigual quanto às condições de acesso ao estudo e ao mercado de trabalho. A inserção diferenciada entre os jovens na população desempregada revela que os jovens negros representam maior número de desempregados que os jovens brancos. Em 2001, o percentual era de 7,1\% de jovens brancos para 9,2\% de jovens negros; em 2009, esta diferença se mantém praticamente estável.

\footnotetext{
${ }^{10}$ Termo utilizado por Nogueira (2004).

${ }^{11}$ Mulheres que só estudam, mulheres que não trabalham/não procuram emprego e não estudam.
} 
DOI: $10.12957 /$ e-mosaicos.2019.46588

Tabela 3 - Distribuição da população jovem, segundo a situação de trabalho e estudo, cor e faixa etária. Brasil ${ }^{1}$, 1992-2009 (em \%)

\begin{tabular}{|c|c|c|c|c|c|c|c|c|c|}
\hline \multirow[b]{2}{*}{ Situação } & \multicolumn{3}{|c|}{ Branco } & \multicolumn{3}{|c|}{ Negro $^{2}$} & \multicolumn{3}{|c|}{ Outros ${ }^{3}$} \\
\hline & $\begin{array}{c}15- \\
19\end{array}$ & \begin{tabular}{|c|}
$20-$ \\
24 \\
\end{tabular} & $\begin{array}{c}25- \\
29\end{array}$ & $\begin{array}{c}15- \\
19\end{array}$ & $\begin{array}{c}20- \\
24\end{array}$ & \begin{tabular}{|c|}
$25-$ \\
29
\end{tabular} & $\begin{array}{l}15- \\
19\end{array}$ & \begin{tabular}{|c|}
$20-$ \\
24 \\
\end{tabular} & \begin{tabular}{|c|}
$25-$ \\
29
\end{tabular} \\
\hline \multicolumn{10}{|c|}{1992} \\
\hline $\begin{array}{l}\text { Trabalha e } \\
\text { não estuda }\end{array}$ & 29,2 & 56,6 & 68,3 & 34,9 & 58,6 & 68,1 & 21,6 & 60,4 & 76,6 \\
\hline $\begin{array}{l}\text { Trabalha e } \\
\text { estuda }\end{array}$ & 20,8 & 11,6 & 4,8 & 18,6 & 8,4 & 3,5 & 26,0 & 13,0 & 6,1 \\
\hline $\begin{array}{l}\text { Desempregado } \\
\text { e estuda }\end{array}$ & 4,6 & 1,6 & 0,4 & 4,1 & 1,8 & 0,4 & 2,8 & 1,8 & 0,0 \\
\hline $\begin{array}{l}\text { Desempre } \\
\text { gado e não } \\
\text { estuda }\end{array}$ & 3,5 & 5,5 & 4,2 & 4,0 & 7,0 & 5,5 & 3,7 & 3,9 & 4,8 \\
\hline \multirow{3}{*}{$\begin{array}{l}\text { Apenas estuda } \\
\text { Não trabalha, } \\
\text { não procura } \\
\text { trabalho e não } \\
\text { estuda } \\
\text { Total }\end{array}$} & 29,8 & 5,9 & 1,2 & 23,4 & 4,1 & 1,0 & 37,2 & 11,4 & 1,6 \\
\hline & 12,0 & 18,7 & 21,0 & 15,0 & 20,1 & 21,5 & 8,7 & 9,5 & 10,8 \\
\hline & 100,0 & 100,0 & 100,0 & 100,0 & 100,0 & 100,0 & 100,0 & 100,0 & 100,0 \\
\hline \multicolumn{10}{|c|}{2001} \\
\hline $\begin{array}{l}\text { Trabalha e } \\
\text { não estuda }\end{array}$ & 16,1 & 49,2 & 64,5 & 17,2 & 48,9 & 61,6 & 9,4 & 33,0 & 67,5 \\
\hline $\begin{array}{l}\text { Trabalha e } \\
\text { estuda }\end{array}$ & 22,6 & 16,6 & 9,5 & 22,1 & 12,8 & 7,6 & 19,5 & 20,9 & 9,7 \\
\hline $\begin{array}{l}\text { Desempregado } \\
\text { e estuda }\end{array}$ & 6,7 & 3,1 & 1,1 & 7,1 & 3,4 & 1,3 & 5,5 & 6,0 & 1,8 \\
\hline $\begin{array}{l}\text { Desempregado } \\
\text { e não estuda }\end{array}$ & 3,8 & 7,0 & 6,0 & 4,0 & 9,2 & 7,8 & 1,7 & 5,5 & 7,6 \\
\hline \multirow{3}{*}{$\begin{array}{l}\text { Apenas estuda } \\
\text { Não Trabalha, } \\
\text { não procura } \\
\text { trabalho e não } \\
\text { estuda } \\
\text { Total }\end{array}$} & 41,8 & 8,8 & 2,6 & 37,4 & 7,2 & 2,4 & 56,0 & 16,9 & 0,0 \\
\hline & 9,0 & 15,2 & 16,4 & 12,1 & 18,4 & 19,2 & 8,0 & 17,7 & 13,4 \\
\hline & 100,0 & 100,0 & 100,0 & 100,0 & 100,0 & 100,0 & 100,0 & 100,0 & 100,0 \\
\hline \multicolumn{10}{|c|}{2009} \\
\hline $\begin{array}{l}\text { Trabalha e } \\
\text { não estuda }\end{array}$ & 16,1 & 51,6 & 67,8 & 16,2 & 53,8 & 65,0 & 12,3 & 43,8 & 63,1 \\
\hline $\begin{array}{l}\text { Trabalha e } \\
\text { estuda }\end{array}$ & 20,0 & 17,3 & 10,1 & 20,5 & 11,5 & 7,9 & 16,1 & 15,1 & 12,8 \\
\hline $\begin{array}{l}\text { Desempregado } \\
\text { e estuda }\end{array}$ & 6,6 & 3,0 & 1,2 & 6,7 & 2,7 & 1,1 & 8,8 & 3,2 & 0,2 \\
\hline $\begin{array}{l}\text { Desempregado } \\
\text { e não estuda }\end{array}$ & 3,9 & 7,4 & 6,1 & 4,6 & 10,0 & 8,4 & 6,9 & 14,2 & 11,8 \\
\hline \multirow{2}{*}{$\begin{array}{l}\text { Apenas estuda } \\
\text { Não trabalha, } \\
\text { não procura } \\
\text { trabalho e não } \\
\text { estuda }\end{array}$} & 44,7 & 8,8 & 2,1 & 41,7 & 5,8 & 2,0 & 42,8 & 7,6 & 1,7 \\
\hline & 8,6 & 11,9 & 12,7 & 10,4 & 16,3 & 15,6 & 13,1 & 16,0 & 10,4 \\
\hline Total & 100,0 & 100,0 & 100,0 & 100,0 & 100,0 & 100,0 & 100,0 & 100,0 & 100,0 \\
\hline
\end{tabular}

Fonte: IBGE - PNAD. Elaboração própria.

As análises feitas, a partir dos dados quantitativos apresentados aqui, evidenciam que a juventude brasileira se apresenta de forma desigual nos quesitos 
idade, sexo e cor. Por outro lado, os dados apresentados iluminam um aspecto já destacado: uma parte significativa da população jovem trabalha e/ou procura emprego. Quase $70 \%$ do contingente total de jovens (15-29 anos), segundo a PNAD (2009), que compõem o que denominamos de "Juventude Trabalhadora Brasileira".

Contudo, por mais que não seja homogênea a juventude inativa brasileira (jovens que só estudam, não estudam, não trabalham e não procuram emprego), sobretudo no que se refere a sexo e cor, há, segundo a PNAD (2009), 43,1\% de jovens adolescentes entre $15-19$ anos, 7,2\% de jovens entre $20-24$ anos e $2,1 \%$ de jovens adultos entre 25-29 anos que só estudam. Para esse grupo, a compreensão de juventude como um momento de espera - "moratória social" - até poderia ser empregada, mas em outro contexto histórico, não esse do momento presente, haja vista que, mesmo para esse grupo privilegiado, esse fato não se sustenta hoje, uma vez que parte significativa das denominadas "condições contemporâneas da vida" se inscreve na insegurança e na transitoriedade ${ }^{12}$.

O sociólogo Robert Castel, em um dos seus artigos, "Les Jeunes ont-ils un rapport spécifique au travail?"13, publicado em 2009, na França, ao analisar as metamorfoses do mercado de trabalho, afirma que houve uma transformação na compreensão do que significa a garantia do trabalho para os jovens deste século, sendo que essa transformação é globalmente marcada por uma precariedade crescente da inscrição da ordem do trabalho e continuamente marcadas pela chancela de insegurança.

Desse modo, por mais Juventude(s) que se possa reconhecer, os dados analisados reiteram a existência de uma juventude específica - com "cara" definida , um grupo gerado cotidianamente pelas relações e contradições sociais entre capital e trabalho. Jovens, como bem evidenciou Pais (2005, p. 17), "[...] que rodopiam por multiplicidade de trabalhos precários, intervalando inserções provisórias no mundo do trabalho com desinserções periódicas".

\section{A JuVEnilização da EJA}

Diante dos dados analisados, podemos afirmar que a grande maioria dos jovens que têm acessado a Educação de Jovens e Adultos (EJA) são aqueles que desde muito cedo conciliam jornadas de trabalho com períodos interrompidos de escolarização. São os jovens que têm seus trânsitos marcados, quase sempre concomitantemente, por extensas jornadas de atividade laboral ou pela busca de um emprego, com horas de investimento pessoal em formação.

\footnotetext{
${ }^{12}$ Como destacaram Melucci (1992) e Vianna (1997)

${ }^{13}$ Os jovens têm uma relação específica com o trabalho? (Tradução nossa).
} 
A relação entre trabalho e educação ganha centralidade para a juventude trabalhadora brasileira. As pesquisas realizadas por Silva $(2008,2012)$ - após a triangulação de macrodados da PEA juvenil com singulares trajetórias investigadas constatam que há, por parte da juventude, um forte discurso em favor da educação como sendo a principal, se não a única, estratégia de mobilidade social ascendente. Jovens que, segundo Silva (2012), desde seus primeiros anos escolares, conviveram com as narrativas de seus pais e avós reiterando que seria ela, a educação, o meio pelo qual eles mudariam de posição na sociedade.

Contudo, se é verdade que trajetórias laborais contribuem para reafirmar que, no Brasil, o trabalho, ou a procura dele, também faz a juventude, igualmente é verdade que as condições objetivas vividas pela grande maioria dos jovens produzem também trajetórias escolares interrompidas ou acidentadas. Assim, a EJA significa esse "(não)lugar"14 que recebe cada vez mais um número expressivo de adolescentes e jovens oriundos da escola denominada "regular." É imperativo demarcar que a EJA não é uma modalidade de ensino "irregular", além disso, hoje ela não possui mais o caráter de suplência.

A frequência da população jovem na EJA vem progressivamente ocupando a atenção de educadores e pesquisadores que estudam a educação, com destaque para essa modalidade de ensino. A presença da população juvenil vem modificando, sobretudo, os cenários educativos e alterando as relações sociais entre os sujeitos inscritos nos diferentes tempos, espaços e gerações.

Esse processo supracitado ganha mais expressividade a partir dos anos 1990, quando alguns autores começam a denominar de "Juvenilização da EJA", em função das evidências empíricas que a presença dos/das jovens já constitui um fenômeno estatístico significativo nas diversas classes de Educação de Jovens e Adultos. Há pouco menos de três décadas, as classes de EJA eram, quase sempre, hegemonicamente constituídas de adultos e idosos que procuravam a modalidade objetivando, sobretudo, a alfabetização.

Atualmente, o desenho das turmas da EJA é outro. Novos sujeitos entram e muitas vezes "roubam a cena", trazendo para o enredo educacional novas e velhas questões desafiadoras. Observando dados mais recentes de matrículas de alunos na EJA realizadas nas escolas de todo país, pode verificar como a Juvenilização se torna cada vez mais um fenômeno expressivo na EJA

\footnotetext{
${ }^{14}$ A EJA pode também se caracterizar um "não lugar", na medida em que não produz e faz sentido para os jovens. Assim, esses sujeitos poderão vivenciar um novo processo de exclusão.
} 
DOI: $10.12957 /$ e-mosaicos.2019.46588

Tabela 4 - Matrículas da EJA entre jovens no Brasil de 2013 a 2016

\begin{tabular}{r|c|c|c|c}
\hline Anos & Total & $\begin{array}{c}\text { Percentual } \\
\text { de queda }\end{array}$ & $\begin{array}{c}\text { Estudantes } \\
\text { entre 15 e } \\
\text { 29 anos }\end{array}$ & $\begin{array}{c}\text { Percentual } \\
\text { de } \\
\text { matrículas }\end{array}$ \\
\hline $\mathbf{2 0 1 3}$ & 3.830 .207 & -- & 2.368 .511 & $61,83 \%$ \\
$\mathbf{2 0 1 4}$ & 3.653 .530 & $9,53 \%$ & 2.270 .845 & $62,15 \%$ \\
$\mathbf{2 0 1 5}$ & 3.491 .869 & $9,55 \%$ & 2.208 .767 & $63,25 \%$ \\
$\mathbf{2 0 1 6}$ & 3.482 .174 & $9,97 \%$ & 2.247 .225 & $64,53 \%$ \\
\hline
\end{tabular}

A faixa etária é calculada considerando a idade do aluno na data de referência do Censo Escolar. Fonte: $\operatorname{INEP}(2013,2014,2015$ e 2016).

É possível observar, a partir dos dados, que as matrículas de EJA vem regredindo com o passar dos anos - uma perda de aproximadamente $10 \%$ dos alunos a cada ano -, o que pode ser observado pelo fechamento do número de turmas ou, até mesmo, de escolas e centros de formação de jovens e adultos em todo país. Contraditoriamente, é possível verificarmos que o número de matrículas entre jovens de 15 a 29 anos apresenta um aumento contínuo, proporcionalmente ao total de matrículas.

Haddad e Di Pierro (2000) destacam que, em 1998, um terço dos estudantes matriculados em cursos de educação de jovens e adultos tinha menos de 18 anos de idade. Há quase duas décadas, esses autores já sinalizavam que a EJA se configurava um mecanismo de aceleração de estudos para jovens com baixo desempenho na escola regular.

A Lei de Diretrizes e Bases (Lei no 9.394/96), no artigo 38, primeiro parágrafo, ao reduzir a idade para a realização de exames de 18 anos para 15 anos, no Ensino Fundamental, e de 21 anos para 18 anos, no Ensino Médio, segundo Soares (2002), vem contribuindo para o aumento significativo do número de jovens que passam a incorporar o quadro de alunos da EJA.

Numa perspectiva crítica, Rummert (2007) reitera que ao reduzir a idade mínima para o acesso a essa forma de certificação, a LDB de 1996 foi determinante na expulsão da escola regular "[...] dos jovens a partir dos 14 anos de idade e evidência a ênfase atribuída a certificação, em detrimento da vivência plena dos processos pedagógicos necessários ao efetivo domínio das bases do conhecimento científico e tecnológico" (RUMMERT, 2007, p. 39).

$\mathrm{Na}$ tentativa de ampliar as causas do aumento significativo de jovens na EJA, Carvalho (2009, p. 1) pontua que:

[...] A juvenilização, intensificada na contemporaneidade, decorre das deficiências do sistema escolar como a evasão e a repetência, que ocasionam a defasagem entre a idade e série; da busca pela 
certificação escolar oriunda da necessidade de trabalhar, da dificuldade de acesso; da ausência de motivação para o retorno a escola, entre outras.

Deste modo, a juvenilização nas turmas da EJA tem se justificado como consequência de problemas estruturais que vêm se apresentando ao longo do tempo, de toda ordem, sejam educacionais ou sociais. Assim, se por um lado é importante destacar a existência de fatores endógenos e/ou que circunscrevem a escola, produtores desse fenômeno, por outro é importante ratificar o quão as condições econômicas e sociais em que se inscrevem os jovens são estruturantes para configurar esse fenômeno. Os dados analisados na seção anterior colocam luz no quanto a condição de ser jovem pobre e trabalhador é um elemento central para esse processo migratório do ensino regular para a EJA.

Sendo assim, estamos diante de um processo que atinge, sobretudo, uma juventude específica brasileira. Jovens que, além de conviver com todos os dilemas próprios de um cotidiano incerto por natureza, buscam uma inscrição no emprego. São jovens que, desde muito cedo, procuram trabalho nas suas várias dimensões e possibilidades e que, no esforço de se inserirem no mercado de trabalho, conciliam, quase sempre, horas de formação - na perspectiva de que esta seja a responsável pela mobilidade social ascendente - com percursos laborais marcados por turbulências, flexibilidade e impermanências.

Nesse duplo movimento identitário entre jovem estudante e jovem trabalhador (empregado ou não), a EJA é acessada por ele pela flexibilidade e disponibilidade que a modalidade proporciona. Embora a escola seja um dos meios, se não o mais importante, para sua mudança de posição social, ela se ajusta as suas demandas reais e objetivas, haja vista que sobreviver constitui seu maior desafio diário.

\section{CONSIDERAÇõES FINAIS}

O presente trabalho objetivou colocar luz sobre a categoria juventude(s), buscando identificar quem são os jovens brasileiros e como eles se relacionam com o trabalho-educação. Além disso, visou analisar em que medida processo de juvenilização da EJA persiste e quem são os jovens que informam esse fenômeno.

A partir da investigação, podemos afirmar que a categoria Juventude é complexa, de modo que gera controversas entre os especialistas da área. Porém, parece haver o consenso de que ela é mais do que uma passagem para a vida adulta - marcada por um período de faixa etária -, pois ela se forja nas relações sociais, por meio das interações concretas e simbólicas que os sujeitos estabelecem nos 
diferentes tempos e territórios. Nessa direção, é legitimo pluralizar as juventudes, haja vista que são múltiplas as formas de se expressar e viver a condição Juvenil.

Contudo, apesar das diversas juventude(s), a relação entre trabalho e educação para muitos brasileiros se torna um elemento estruturante na construção da sua identidade juvenil, haja vista que, conforme os dados da PEA analisados aqui, a sua grande maioria estuda e trabalha. São jovens que, além de viverem questões próprias da condição juvenil, buscam, desde muito cedo, uma inscrição na sociedade salarial ou, dito de outro modo, um estatuto de empregado. Os dados da pesquisa reiteram que, no Brasil, o trabalho, ou a procura dele, também faz a juventude.

Trata-se, portanto, de uma juventude que não usufrui de um período exclusivo de preparação para a vida adulta, nem de um tempo destinado à formação para o futuro ingresso no mercado de trabalho, como apregoava a concepção moderna de juventude - "moratória social". À luz dos dados estatísticos apresentados aqui, conclui-se que os trânsitos desse grupo social são marcados, quase sempre concomitantemente, por longas jornadas de atividade laboral, ou pela busca de um emprego, dedicando horas de investimento pessoal para a formação.

A dupla vivência de construção de trajetórias, ora de formação, ora de trabalho, revela o quanto elas são interdependentes, sobretudo, se tratando de jovens pobres, em particular. Emir Sader, em 2005, no prefácio à obra de Isteván Mészáros, Educação para além do capital, provoca a análise dessa relação indagando: "[...] digam-me onde está o trabalho em um tipo de sociedade e eu direi onde está a educação. Em uma sociedade do capital, a educação e o trabalho se subordinam a essa dinâmica, da mesma forma que em uma sociedade em que se universalize o trabalho - uma sociedade em que todos se tornem trabalhadores -, somente aí se universalizará a educação" (SADER, 2005, p. 17).

Portanto, a migração dos jovens da educação dita "regular" para a EJA tem, majoritariamente, uma classe social definida. São, quase sempre, os mesmos jovens que desde muito cedo conciliam tempos de estudo com a condição de "interino permanente" (CASTEL, 1998), homens e mulheres que andam de emprego em emprego na esperança de uma estabilidade e melhores condições de trabalho. Assim, além de constituírem o grupo etário mais desfavorecido pelas condições restritivas de emprego, também precisam, muitas vezes, "abandonar" a escola e construir seus itinerários marcados por trajetórias escolares incompletas.

É possível afirmar que cada vez mais esses jovens (leia-se a juventude trabalhadora) estão acessando a EJA, consolidando o que os autores já apontavam desde a década de 1990 como o fenômeno da juvenilização da EJA. Dito de outra forma: a relação estabelecida pela juventude brasileira ao longo dos anos com o trabalho e a educação é estruturante para consolidação e permanência do fenômeno da juvenilização da/na EJA. Portanto, ao longo da pesquisa, constatou-se que o fenômeno da juvenilização dessa modalidade de ensino em todo o país ainda persiste e apresenta em processo contínuo de crescimento. 
Assim, as classes de EJA cada vez mais apresentam características etárias bastante distintas, classes de e/com tempo geracionais diversos, modificando o cotidiano escolar e as relações que se estabelecem entre os sujeitos que ocupam esse espaço (BRUNEL, 2004). No entanto, é imperativo destacar que, apesar das novas configurações que esse fenômeno demanda de todos que o constroem cotidianamente a EJA - sejam jovens, adultos ou idosos -, trata-se de homens e mulheres que já foram/são marginalizados nas esferas socioeconômicas e educacionais.

Frente ao exposto, a pesquisa informa que estamos diante de um fenômeno complexo, que envolve múltiplos fatores relacionais e, portanto, demanda novas pesquisas e aprofundamentos, destacadamente no que se refere às suas relações com Ensino Fundamental e Médio chamado de "ensino regular", bem como com as mudanças contemporâneas do mundo do trabalho.

\section{REFERÊNCIAS}

ALVES, N. Juventudes e Inserção Profissional. Educa-Unidade de I\&D de Ciências da Educação, 2008

ANDRADE, E. R. Os jovens da EJA e a EJA dos jovens. In: Oliveira, I. B. De \& Paiva, J. (Orgs.). Educação de jovens e adultos. (pp. 43-54). Rio de Janeiro: DP\&A, 2004

Lei no 9.394, de 20 de dezembro de 1996. Estabelece as diretrizes e bases da educação nacional. Brasília, 1996. Recuperado em 17 fevereiro, 2016, de http://www.planalto.gov.br/ccivil 03/leis/L9394.htm. 1996

BRUNEL, C. Jovens cada vez mais jovens na educação de jovens e adultos. Porto Alegre: Mediação, 2004

BOURDIEU, P. A. "Juventude" é apenas uma palavra in Questões de Sociologia. Rio de Janeiro: Editora Marco Zero, 1983

CARRANO, P. C. R. Juventudes: as identidades são múltiplas. Movimento. Revista da Faculdade Revista de Informação Legislativa de Educação da Universidade Federal Fluminense, 1, 11-26, 2000 
DOI: $10.12957 /$ e-mosaicos.2019.46588

CARVALHO, R. V. A juventude na educação de jovens e adultos: uma categoria provisória ou permanente? In: $9^{\circ}$ Congresso Nacional de Educação / 30 Encontro Sul Brasileiro de Psicopedagogia. Paraná, 2009

CASTEL, Robert. As metamorfoses da questão social: uma crônica do salário. (I. D. Poleti, Trad.). Petrópolis, RJ: Vozes, 1998

Dayrell, J. (2003, setembro-dezembro). O jovem como sujeito social. Revista Brasileira de Educação, 24, pp. 40-52.

DENZIN, N. K. \& LINCOLN, Y. S. O planejamento da pesquisa qualitativa. Porto Alegre, Penso, 2006

FORACCHI, M. M. O estudante e a transformação da sociedade brasileira. São Paulo, Companhia Editora Nacional, 1965

GALLAND, O. Les jeunes. Paris: La Découverte, 1996

GIL, A. C. Métodos e técnicas da pesquisa social (6a ed.). São Paulo: Editora Atlas, 2008

HADDAD, S. \& DI PIERRO, M. C. Escolarização de jovens e adultos. Revista Brasileira de Educação, 14, pp. 108-130, 2000

MELUCCI, A. Il gioco dell'/o. Milão: Saggi/Feltrinelli, 1992

NOGUEIRA, C. M. A. Feminização no mundo do trabalho. Campinas, SP: Autores Associados, 2004

PAIS, J. M. A construção sociológica da juventude - alguns contributos. Análise Social, 105-106(25), pp. 139-16, 1990

PAIS, J. M. Culturas juvenis. Lisboa: Imprensa Nacional Casa da Moeda, 1993

PAIS, J. M. Ganhos, tachos e biscates: jovens, trabalho e futuro. Lisboa: Ambar, 2005

PAIVA, V. P. Educação popular e educação de adultos. São Paulo: Edições Loyola, 1987

PERALVA, A. O jovem como modelo cultural. Revista Brasileira de Educação, São Paulo, 5/6, pp. 15-24, 1997 
RUMMERT, S. M. A "marca social" da Educação de Jovens e Adultos trabalhadores. IV Simpósio Trabalho e Educação. Rio de Janeiro, 2007

SADER, E. Prefácio. In: Mészáros, I. Educação para além do capital. São Paulo: Boitempo Editorial, 2005

SPOSITO, M. P. Juventude e escolarização. Brasília DF: MEC/Inep/Comped. (Série Estado do Conhecimento - no 7). Recuperado em 17 fevereiro, 2016, de www.publicacoes.inep.gov.br>. 2002

SILVA, J. H. da. Juventude trabalhadora brasileira: percursos laborais, trabalhos precários e futuros (in)certos. Tese de Doutorado. Universidade Estadual de Campinas, Campinas, S. P., Brasil, 2012

SILVA, J. H. da. Os filhos do desemprego: jovens itinerantes do primeiro emprego. Brasília: Liber Livro, 2009

SOARES. L. J. G. Educação de jovens e adultos. Rio de Janeiro: DP\&A, 2002

VIANNA, H. "Introdução". In: Vianna, H. (Org.). Galeras cariocas. Rio de Janeiro: Editora da UFRJ, 1997

Recebido em 10 de novembro de 2019

Aceito em 23 de novembro de 2019

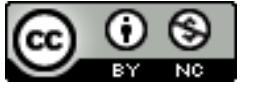

A e-Mosaicos Revista Multidisciplinar de Ensino, Pesquisa, Extensão e Cultura do Instituto de Aplicação Fernando Rodrigues da Silveira (CAp-UERJ) está licenciada com uma Licença Creative Commons - Atribuição-NãoComercial 4.0 Internacional.

Os direitos autorais de todos os trabalhos publicados na revista pertencem ao(s) seu(s) autor(es) e coautor(es), com o direito de primeira publicação cedido à e-Mosaicos.

Os artigos publicados são de acesso público, de uso gratuito, com atribuição de autoria obrigatória, para aplicações de finalidade educacional e não-comercial, de acordo com o modelo de licenciamento Creative Commons adotado pela revista. 